\title{
Is Bedside Ultrasound a Reliable Method for Detecting Soft Tissue Foreign Bodies in Upper Extremity Penetrating Trauma Patients?
}

\author{
Ehsan Bolvardi ${ }^{1}$; Masoud Pezeshki Rad ${ }^{2}$; Bita Abbasi ${ }^{3}$; Reza Akhavan ${ }^{1,}$ \\ ${ }_{1}^{1}$ Department of Edalatian Emergency, Imam Reza Hospital, School of Medicine, Mashhad University of Medical Sciences, Mashhad, IR Iran \\ $2_{2}$ Vascular and Endovascular Surgery Research Center, Imam Reza Hospital, School of Medicine, Mashhad University of Medical Sciences, Mashhad, IR Iran \\ 3 Department of Radiology, Imam Reza Hospital, School of Medicine, Mashhad University of Medical Sciences, Mashhad, IR Iran \\ ${ }^{*}$ Corresponding author: Reza Akhavan, Department of Edalatian Emergency, Imam Reza Hospital, School of Medicine, Mashhad University of Medical Sciences, Mashhad, IR Iran. Tel: \\ +98-9153133679, Fax:+98-5118525312, E-mail: akhavanr901@mums.ac.ir
}

Received: July 15, 2014; Revised: August 19, 2014; Accepted: August 24, 2014

\begin{abstract}
Background: Detection of foreign bodies trapped in the soft tissue is a diagnostic problem in patients with penetrating trauma referring to the emergency department. In spite of increasing advances in imaging modalities, detection of foreign bodies trapped in the subcutaneous tissue is still problematic. Among the methods available for the detection of foreign bodies, radiography is the most accessible modality, but it can only diagnose radiopaque objects. CT scan has some limitations including cost and radiation. MRI is very expensive and is not always available. Ultrasound is an easy, inexpensive and accessible method and has no radiation risk. It also provides simultaneous imaging and is bed side available and effective, especially in detection of radiolucent foreign bodies.

Objectives: So the new clinical question is that: "Is bedside ultrasound a reliable method for detecting soft tissue foreign bodies in upper extremity penetrating trauma patients?"

Patients and Methods: 112 patients with penetrating trauma of volar surface of hand and wrist were enrolled in this study. All patients were clinically suspicious of tendon injury that made them be candidates for diagnostic surgical exploration. Before the surgery, the patients signed a consent form and then a thorough ultrasonography was performed to evaluate the presence of any foreign bodies. The results were then compared with the records of radiography as well as clinical reports of emergency physician and surgeon.

Results: Among 112 patients under study, foreign body was detected in 21 patients through clinical examination or surgery, out of which 18 (85.71\%) cases were detected by ultrasonography; whereas, radiography was able to detect 16 cases (76.19\%). False positive results reported one case (1.1\%) in ultrasonography and $0(0 \%)$ in radiography.

Conclusions: Ultrasonography seems to be a safe and cost effective method to evaluate foreign bodies, especially radiolucent objects, in patients with penetrating trauma and suspicious of foreign bodies that may remain undiagnosed in radiography. Availability of bedside ultrasound for emergency physicians is an important issue, since it is not possible to access the radiologist at any time of the day and night. On the other hand, treatment of patients in emergency department is a cost-effective way, as it reduces the number of surgical explorations that are merely diagnostic and it is also time and cost-consuming for therapeutic system.
\end{abstract}

Keywords:Trauma; Upper Extremity; Patients

\section{Background}

In $2 \%$ of penetrating trauma cases, foreign bodies are retained in the tissues. Some of these foreign bodies are obvious in the initial physical examination and will be removed, but in many cases, subcutaneous foreign bodies are not detected in the initial assessment and may cause morbidity because of remaining in the tissue (1). In the absence of timely diagnosis and removal, foreign bodies trapped in the soft tissue can cause toxic and allergic reactions, inflammation and infection (2). Retained foreign bodies constitute a large fragment of medico-legal issues against emergency physicians. In patients with penetrating trauma who refer to the emergency department, detection of foreign bodies is still problematic and can be one of the main reasons bringing a lawsuit against emergency medicine specialists (3). This problem is what brings the question of finding the best method for diag- nosis of soft tissue foreign bodies into the era of investigation. Although radiography has been historically the most accessible modality for the detection of foreign bodies, it can only diagnose radiopaque objects. Xerography is a special radiographic technique that facilitates the detection of foreign bodies by indicating the edges of the object. But a special tool is required for this technique and it is not easily accessible (4). CT scan can also detect radiolucent objects but it has some limitations including cost and radiation (5). MRI can detect radiolucent objects as well but it is very expensive and is not always available. Ultrasound is an inexpensive and accessible method, with no radiation risk. It is about two decades that this method has been accepted as a means to evaluate musculoskeletal structures and superficial soft tissues. Unfortunately, the position of this modality in the evaluation

Copyright (C) 2014, Razavi Hospital. This is an open-access article distributed under the terms of the Creative Commons Attribution-NonCommercial 4.0 International License (http://creativecommons.org/licenses/by-nc/4.0/) which permits copy and redistribute the material just in noncommercial usages, provided the original work is properly cited. 
Bolvardi E et al.

of these structures is still unknown in many countries including our country (6). This method has recently been used to detect foreign bodies. Having no radiation risk, providing simultaneous imaging and bedside availability are among the advantages of this method. Studies on the ability of ultrasound to detect foreign bodies indicate promising results $(7,8)$.

\section{Objectives}

So the new clinical question is that: "Is bedside ultrasound a reliable method for detecting soft tissue foreign bodies in upper extremity penetrating trauma patients?"

\section{Patients and Methods}

This study was performed on 112 patients with upper extremity penetrating trauma who were visited in the Emergency Department of Imam Reza and Shahid Hashemi Nejad Hospitals of Mashhad. These patients were the ones who were either suspicious of tendon rupture in the clinical examination or did not cooperate in the examination, so it made them be candidates for diagnostic surgical exploration.

Inclusion criteria were as follows:

1) Patients over 18 years-old

2) Penetrating injury to the volar surface of hands and wrists

3) Lack of associated open fractures

4) Lack of traumatic amputation
5) Mandatory surgical exploration according to physical examination

Exclusion criteria were as follows:

1) Associated open fractures

2) Burns and crush injuries

3) Amputations

Before the surgery, all the patients signed a consent form and then a thorough ultrasonography and radiography were performed to evaluate the presence of any foreign bodies. The results were recorded and then the surgical reports in terms of the presence of foreign bodies were recorded as well. All sonographic evaluations were performed by emergency medicine residents. The required training course for detection of foreign bodies through ultrasonography was conducted in a week under the supervision of radiologist assistant. All ultrasound imaging in Imam Reza Hospital was performed using a Sonosite and linear transducer $(12 \mathrm{MHz}$ ) and in Shahid Hashemi Nejad Hospital by $10 \mathrm{MHz}$ linear transducer.

\section{Results}

Among 112 patients under study, foreign body was detected in 21 patients through clinical examination or surgery, out of which 18 (85.71\%) cases were detected by ultrasonography; whereas, radiography was able to detect 16 cases (76.19\%). False positive results were reported one case $(1.1 \%)$ in ultrasonography and $0(0 \%)$ in radiography (Tables 1 - 6).

\begin{tabular}{|c|c|c|c|c|c|c|c|c|c|}
\hline \multirow{2}{*}{$\begin{array}{l}\text { Ultrasonography } \\
\text { Surgery }\end{array}$} & \multicolumn{3}{|c|}{ Yes } & \multicolumn{3}{|c|}{ No } & \multicolumn{3}{|c|}{ Total } \\
\hline & Number & $\begin{array}{c}\text { Column } \\
\text { percentage }\end{array}$ & $\begin{array}{c}\text { Row } \\
\text { percentage }\end{array}$ & Number & $\begin{array}{c}\text { Column } \\
\text { percentage }\end{array}$ & $\begin{array}{c}\text { Row } \\
\text { percentage }\end{array}$ & Number & $\begin{array}{c}\text { Column } \\
\text { percentage }\end{array}$ & $\begin{array}{c}\text { Row } \\
\text { percentage }\end{array}$ \\
\hline Yes & 18 & 71.85 & 74.94 & 1 & 1.1 & 26.5 & 19 & 96.16 & 100 \\
\hline No & 3 & 29.14 & 33.3 & 90 & 9.98 & 77.96 & 93 & 03.83 & 100 \\
\hline Total & 21 & 100 & 75.18 & 91 & 100 & 25.81 & 112 & 100 & 100 \\
\hline
\end{tabular}

a Measure of agreement kappa $=1$

$\mathrm{b}_{\mathrm{P} \text { value }}=0.0001$.

Table 2. Sensitivity of Ultrasonography in Detection of Foreign Bodies ${ }^{a}$

\begin{tabular}{lcccccc}
\hline Sensitivity & Specificity & False Negative & False Positive & $\begin{array}{c}\text { Positive Predictive } \\
\text { Value }\end{array}$ & $\begin{array}{c}\text { Negative Predictive } \\
\text { Value }\end{array}$ & $\begin{array}{c}\text { Precision } \\
\text { Accuracy }\end{array}$ \\
\hline $\mathbf{7 1 . 8 5}$ & 90.98 & 29.14 & 1.1 & 74.94 & 77.96 & 43.96 \\
\hline
\end{tabular}

a Data are presented as \%.

Table 3. Sensitivity of Radioography in Detection of Foreign Bodies a, b

\begin{tabular}{|c|c|c|c|c|c|c|c|c|c|}
\hline \multirow{2}{*}{$\begin{array}{l}\text { Surgery } \\
\text { ultrasonography }\end{array}$} & \multicolumn{3}{|c|}{ Yes } & \multicolumn{3}{|c|}{ No } & \multicolumn{3}{|c|}{ Total } \\
\hline & $\begin{array}{c}\text { Column } \\
\text { Percentage }\end{array}$ & $\begin{array}{c}\text { Row } \\
\text { Percentage }\end{array}$ & Number & $\begin{array}{c}\text { Column } \\
\text { Percentage }\end{array}$ & $\begin{array}{c}\text { Row } \\
\text { Percentage }\end{array}$ & Number & $\begin{array}{c}\text { Column } \\
\text { Percentage }\end{array}$ & $\begin{array}{c}\text { Row } \\
\text { Percentage }\end{array}$ & Number \\
\hline Yes & 16 & 19.76 & 100 & 0 & 0 & 0 & 16 & 29.14 & 100 \\
\hline No & 5 & 81.23 & 21.5 & 91 & 100 & 79.94 & 96 & 71.85 & 100 \\
\hline Total & 21 & 100 & 75.18 & 91 & 100 & 25.81 & 112 & 100 & 100 \\
\hline
\end{tabular}

$\mathrm{a}$ Measure of agreement kappa $=0.839$

$\mathrm{b}_{\text {Pvalue }}=0.0001$. 
Bolvardi E et al.

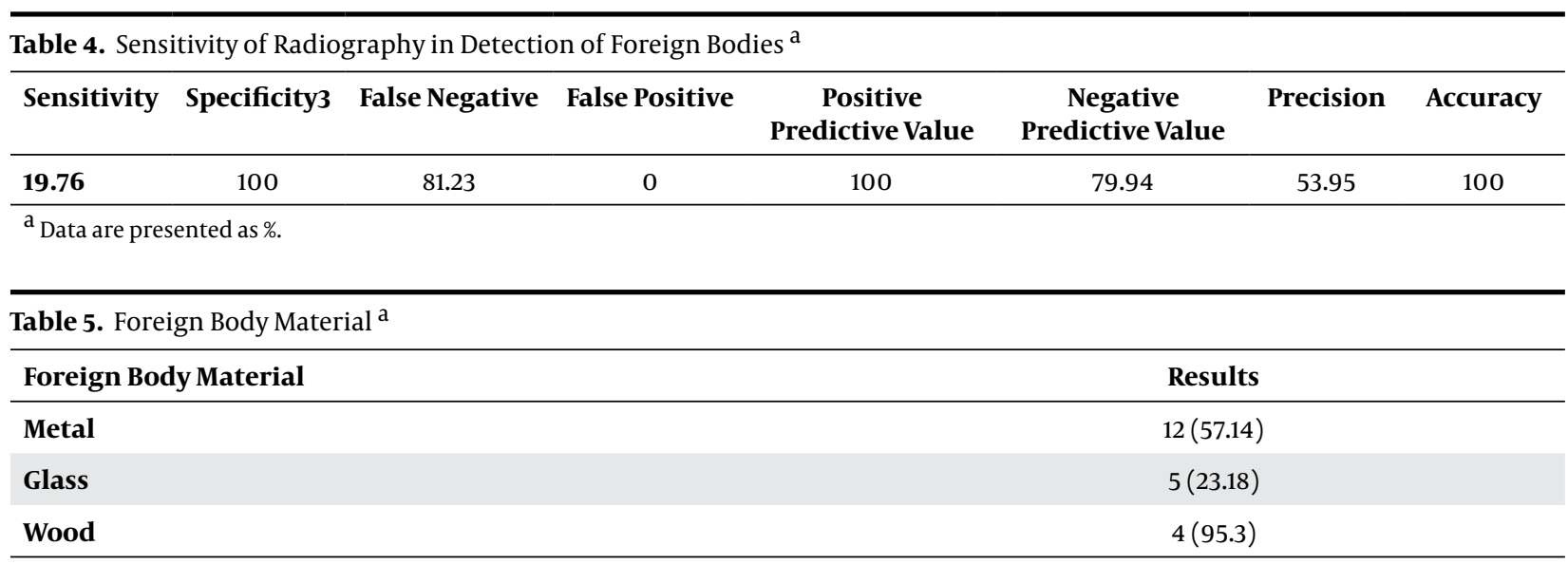

a Data are presented as No.(\%).

Table 6. The Percentage of Detected Foreign Bodies Through Radiography and Ultrasonography Based on the Material of Them a

\begin{tabular}{lcc}
\hline Foreign Body Material & $\begin{array}{c}\text { Detected Foreign Bodies Through } \\
\text { Radiography }\end{array}$ & $\begin{array}{c}\text { Detected Foreign Bodies Through } \\
\text { Ultrasonography }\end{array}$ \\
\hline Metal & $12(100)$ & $11(91.67)$ \\
Glass & $3(60)$ & $4(80)$ \\
Wood & $1(25)$ & $3(75)$ \\
\hline
\end{tabular}

a Data are presented as No. (\%).

\section{Discussion}

In this study, we used ultrasound to evaluate presence of foreign bodies in the soft tissue of patients referred to emergency department for penetrating hand and wrist injuries. All patients were candidates of surgical exploration for suspected tendon injuries and the presence of foreign body was approved in the same procedure. The results were compared with radiography that was historically considered as the first line investigation to detect foreign bodies. We showed a sensitivity of $85.7 \%$ and specificity of $98.9 \%$ for ultrasound in detecting soft tissue foreign bodies, while radiography revealed a sensitivity of $76.19 \%$ and specificity of $100 \%$ in detecting foreign bodies. The higher specificity is due to a case of false positive result in ultrasound examination. This is the result of more artifacts in ultrasound such as shadows from normal fibrous bands in soft tissues. But what is more important for a diagnostic test to be introduced as a first line study is its higher sensitivity and lower rate of false negatives leading to higher negative predictive value. In plain radiography, some foreign bodies, especially wooden objects may remain undiagnosed. These objects are radiolucent and added to the false negative results of radiography. In this study, three out of four wooden foreign bodies were detected by ultrasound, but just one case could be detected by plain radiography.

A quite similar study was conducted by Crawford and Matheson. They evaluated 39 patients suspected to foreign bodies by negative radiographic studies using ultrasound and reported 20 cases of foreign bodies, among which two cases proved as false positive in the subsequent surgery (9). Generally, organic materials such as thorn, wood and fish bones have low density in radiography and may remain undetected. Although materials such as plastic and glass are radiopaque, they may remain undetected in plain radiography due to the lower density (10). Detecting foreign bodies in the wound requires high degrees of clinical suspicion. Even the smallest puncture wounds are at the risk of having missed foreign bodies. Some issues such as altered mental status due to head trauma, associated toxicity and insufficient attention make the patient's history less reliable in detecting foreign bodies. Opaque foreign bodies such as metal and glass particles are easily detected in the plain radiography but plastic materials have less density and may go undetected (2). Wood, thorn and aluminum are radiolucent and cannot be detected by plain films (11). Wood particles can cause severe infections in the soft tissue and they must be removed. Ultrasonography has been used to detect and remove foreign bodies since 1978. Reflection of ultrasound beam in the tissue is at most when acoustic difference between foreign body and soft tissue is at the highest level. This increases the ability of ultrasound to detect the foreign body. Successful imaging of reflected beams depends on the size, shape, orientation and the foreign material composition and type and frequency of the probe. In ul- 
trasonography, just the proximal surface of the object is visible. When an object is perpendicular to the sound, a greater proportion of beams are reflected and better images would be created. Small metal foreign bodies, such as shrapnel could cause comet tail artifact. The artifact is created at the boundary between the foreign body and tissue as the consequence of repeated sound wave echoes (2). Using stand-off gel and immersing the organ in water bath are among the techniques that can be used for better evaluation of surface textures. Dynamic ultrasonography should be performed at least in two tissue plans. Most foreign bodies are hyperechoic and inflammatory changes that they induce in the adjacent tissue are seen in the form of hyperechoic rim. At least 24 hours are required to make these inflammatory changes (10). Glass and metal objects create comet tail artifacts, but stone particles have posterior shadowing. The amount of foreign body echo in ultrasonography depends on the acoustic impedance. This factor varies according to the density of the object. For this reason, metal foreign bodies have higher echo than glass and wood. But non-opaque foreign bodies with low density are visible and could reflect the ultrasound beam sufficiently. Like subcutaneous fat, hyperechoic foci in echoic tissue have edematous muscle or tissue, so they will be diagnosed more easily when they are accompanied by reverberation or comet tail artifacts. In this study, the sensitivity and accuracy rate for the detection of foreign bodies through ultrasonography were reported $71.85 \%$ and $91.94 \%$ respectively that are acceptable and higher than other older studies $(1,2,7,8)$. This could be due to using newer devices and ultrasound probes with higher frequency as well as performing sonography after the required training course. On the other hand, most researchers have done their studies on synthetic samples. This can cause bias in the studies. Although synthetic samples have been prepared in compliance with all aspects of the sample standardization, there is lack of tissue diversity and they cannot evaluate the sonography skills of the operator in the real situation and patient's bedside. Although emergency medicine center of Mashhad University of Medical Sciences is a referral center with high number of patients, study on real patients was possible. At the bedside of the patients with penetrating trauma, the presence of gas in soft tissue due to trauma, inability of the operator to obtain the desired position, lack of patient cooperation and possible foreign body in different depths of the skin are among the factors that make ultrasonography more difficult. However, ultrasonography seems to be a safe and cost-effective method to detect foreign bodies, especially radiolucent objects, in patients with penetrating trauma and suspicious to foreign bodies that may remain undiagnosed in radiography. Availability of bedside ultrasound for the purpose of detection and removal of the foreign body is an important issue for emergency physicians, since radiologists are not available on a 24-hour-a-day basis. On the other hand, treatment of patients in the department of emergency medicine is a cost-effective way as it reduces the number of surgical explorations that are merely diagnostic and it is also time- and cost- consuming for therapeutic system. This also prevents the process of patients' coming back with delayed soft tissue infections and also reduces the amount of patients' law suits against emergency medicine specialists. Limitations of ultrasonography in the evaluation of foreign bodies is due to the fact that only superficial aspects of these objects are visible in ultrasonography and evaluation of the exact shape and three-dimensional position of them is not possible. This can create some limitations for the removal of foreign body with ultrasound guidance. Finally, we think that ultrasonography is an available and cost-effective method for diagnosing soft tissue foreign bodies. According to the sensitivity and specificity reported in our study and some older studies, we think this method can substitute radiography as the first line study to detect foreign bodies in extremities. However, more studies with greater sample volumes may be needed.

\section{Acknowledgements}

This article was derived from Dr. Akhavan's graduate thesis entitled "evaluating diagnostic accuracy of ultrasound examination in the diagnosis of tendon injuries in hand and finger trauma" for emergency medicine residency.

\section{Funding/Support}

This research was financially supported by a grant provided by the Chancellor for Research of Mashhad University of Medical Sciences, Mashhad, Iran. We are grateful to all patients for their kind participation. The statistical advices of Mr. Meshkat are appreciated as well.

\section{References}

1. Paziana K, Fields JM, Rotte M, Au A, Ku B. Soft tissue foreign body removal technique using portable ultrasonography. Wilderness Environ Med. 2012;23(4):343-8.

2. Lammers R. Soft tissue foreign bodies. Ann Emerg Med. 1988;17(12):1336-47.

3. Karcz A, Holbrook J, Auerbach BS, Blau ML, Bulat PI, Davidson A, et al. Preventability of malpractice claims in emergency medicine: A closed claims study. Ann Emerg Med.1990;19(8):865-73.

4. Benzer DG, Anderson W. Levels of physician responsibility in diagnosis and treatment of addiction. Wis MedJ.1992;91(9):533-5.

5. Flom LL, Ellis GL. Radiologic evaluation of foreign bodies. Emerg Med Clin North Am. 1992;10(1):163-77.

6. Gilbert FJ, Campbell RS, Bayliss AP. The role of ultrasound in the detection of non-radiopaque foreign bodies. Clin Radiol. 1990;41(2):109-12.

7. Fornage BD, Schernberg FL. Sonographic diagnosis of foreign bodies of the distal extremities. AJR Am J Roentgenol. 1986;147(3):567-9.

8. Mizel MS, Steinmetz ND, Trepman E. Detection of Wooden Foreign Bodies in Muscle Tissue: Experimental Comparison of Computed Tomography, Magnetic Resonance Imaging, and Ultrasonography*. Foot Ankle Int. 1994;15(8):437-43.

9. Crawford $\mathrm{R}$, Matheson AB. Clinical value of ultrasonography in 


\section{Bolvardi E et al.}

the detection and removal of radiolucent foreign bodies. Injury. 1989;20(6):341-3.

10. Ipaktchi K, Demars A, Park J, Ciarallo C, Livermore M, Banegas R. Retained palmar foreign body presenting as a late hand infec- tion: proposed diagnostic algorithm to detect radiolucent objects. Patient Saf Surg. 2013;7(1):25.

11. Mucci B, Stenhouse G. Soft tissue radiography for wooden foreign bodies--a worthwhile exercise? Injury. 1985;16(6):402-4. 